\title{
Clinical Usefulness of Shoulder Stability Exercises for Middle-aged Women
}

\author{
Seok-Hwa Chol, PT, MSc1), Byoung-Hee Lee, PT, PhD²** \\ 1) Graduate School of Physical Therapy, Sahmyook University, Republic of Korea \\ 2) Department of Physical Therapy, Sahmyook University: 815 Hwarang-ro, Nowon-gu, Seoul 139-742, \\ Republic of Korea
}

\begin{abstract}
Purpose] This study examined the clinical usefulness of shoulder stability exercises and the effect of stability exercise on the shoulder pain of middle-aged women. [Subjects] Twenty-two middle-aged female subjects were randomly divided into two groups: a shoulder stability exercise group (Experimental group, $\mathrm{n}=11$ ) and a control group ( $\mathrm{n}=11)$. [Methods] Subjects in the experimental group performed a shoulder stability exercise, which was designed to correct abnormal location of the scapula, for 40 minutes per day, three times per week, over a period of four weeks. Range of motion, muscle strength, and grasping power were measured to determine the effect of the shoulder stability exercise. The measured parameters were evaluated before and after four weeks of exercise. [Results] Following intervention, range of motion, muscle strength, and grasping power showed greater improvements in the experimental group than in the control group. [Conclusion] The results of this study show that shoulder stability exercise can improve the shoulder function of middle-aged women, and prevent damage to the shoulder joint. We consider this exercise would be useful in clinical rehabilitation.

Key words: Middle-aged women, Shoulder dysfunction, Shoulder stability
\end{abstract}

(This article was submitted Apr. 10, 2013, and was accepted May 15, 2013)

\section{INTRODUCTION}

Shoulder pain and dysfunction are related to location of the scapula at rest, and abnormal movement ${ }^{1)}$, abnormal location of the scapula, instability of movement relative to the shoulder joint, rotator cuff rupture, and impingement syndrome ${ }^{2-4)}$. Scapula damage syndrome is caused by movement in the easiest direction in abnormal movement, and can cause pain with repetitive stress in that specific direction $^{5)}$. Therefore, an abnormal location of the scapula caused by abnormal muscle action around the shoulder joint can lead to limitation of scapulothoracic joint movement. Eventually, this causes stress to the joint capsule of the scapulohumeral joint causing impingement syndrome and instability in the shoulder girdle ${ }^{6}$.

Therapeutic interventions for shoulder pain uses hyperthermia, cryotherapy, ultrasound, massage, TENS, injection, and acupuncture. Most of these interventions can relieve pain but are inefficient at preventing recurrence of pain and maintenance of normal function. Therefore, in the present study, shoulder joint stabilization exercise was prescribed for patients with shoulder pain. Stability of the shoulder joint is important, however, stability and muscle strengthening is more important because the shoulder is very mobile. Among the muscles that act to maintain shoulder stability, the serratus anterior is important for maintaining scapulohumeral rhythm ${ }^{7}$. When elevating the upper

${ }^{*}$ To whom correspondence should be addressed.

E-mail: 3679@syu.ac.kr limb, it helps upward rotation and posterior tilt /retroversion of the scapula and holds the scapula to the thoracic cage to prevent winging scapula ${ }^{8)}$.

During full range of motion (ROM) movement of the shoulder joint, the strength of the rotator cuff simultaneous activity of the scapular and the scapulohumeral condition $^{3,6)}$, instability of the scapula, and abnormal movement are the main cause of impingement syndrome. Preventing impingement syndrome and restoration of mobility and stability are important, and the trapezius and the serratus anterior play important role ${ }^{6,7)}$. Weakness of the lower trapezius has negative effects on scapular movement, increasing shoulder joint weakness, and can be a cause of worsening of the lower trapezius is the main muscle maintining appropriate posture and alignment of the shoulder joint ${ }^{3,7)}$. The serratus anterior also works to provide stability of the scapula. It maintains the appropriate location of the scapula together with the lower trapezius ${ }^{9}$. Excessive activation of the upper trapezius decreases a subject's ability to control the lower trapezius and the serratus anterior, and may be a cause of shoulder pain.

This study prescribed stability exercise for normal location of the scapula and muscle balance in order to determine its effect on ROM and strength, and to provide basic information for rehabilitation of patients with shoulder pain.

\section{SUBJECTS AND METHODS}

A total of 22 middle-aged females with shoulder pain, who voluntarily agreed to participate in the shoulder stability exercise were included in this study. The subjects were 
randomly divided into an experimental group and a control group. Range of motion, muscle strength, and grasping power were tested. The side exhibiting the least pain was called the superior side, and the side exhibiting the greatest pain was called the inferior side; measurements were performed on both sides. The stability exercise for the shoulder was performed three times per week, 40 minutes per performance, for a total of four weeks. General characteristics of the subjects in the experimental group were: a mean age of 44.0 years, a mean height of $161.45 \mathrm{~cm}$, and a mean weight of $60.36 \mathrm{~kg}$; subjects in the control group 46.36 years, mean height $161.36 \mathrm{~cm}$, mean weight of $60.64 \mathrm{~kg}$. There were no significant differences between the groups. The present study was approved by Sahmyook University Institutional Review Board. All participants were given an explanation of the objective of the study and its requirements, and all those who participated provided their written informed consent.

Stability exercises for the shoulder joint were designed to correct abnormal location of the scapula. In order to strengthen the serratus anterior, a push-up exercise was performed, with maintenance of scapular protraction for 5-10 seconds in a closed-chain motion. For the first 1-2 weeks, knee push-ups were performed, then the standard pushup was performed in order to achieve a gradual increase of exercise intensity. However, those who were not able to perform the standard push-up exercise received assistance in order to relieve the load by placement of a cushion under the knees and to prevent spinal curvature.

The exercise for strengthening of the lower trapezius minimized the muscle activity of the upper trapezius, and, at the same time, maximized the muscle activity of the lower trapezius by performance of the modified prone cobra, as suggested by Arlotta ${ }^{10)}$. For the first 1-2 weeks, prone row was performed, and, then modified prone cobra was performed in order to achieve a gradual increase in exercise intensity.

The Codman exercise was performed for orderly improvement of flexion, abduction, extension, and adduction around the cone when a circle is drawn on the scapulohumeral joint ${ }^{11)}$, and a $3 \mathrm{~kg}$ weight was added in order to provide pulling capacity ${ }^{1}$. The exercise was performed as if drawing a circle using clockwise rotation and anticlockwise rotation. Trapezius exercise causes rotation and abduction of the scapula aiming to create sufficient movement in the middle and lower fibers of the trapezius. Subjects received a thorough explanation on how to perform the same scapular motion for both sides in order to provide help with scapular rhythm; the exercise is performed like the motion of a wall clock.

For stretching of the pectoralis minor, subjects stood beside a doorframe and performed pectoralis minor selfstretching ${ }^{12)}$. During this exercise, the subjects' bodies were examined carefully to determine whether it was inclined or rotating. The position of the hand was changed in order to stretch the whole of the pectoralis muscle.

Holding the arm out in a line is a closed-chain exercise involving the elbow, which helps to stabilize the upper limb and body. For those who were not able to perform this ac- tion, a cushion was placed under their knees in order to decrease weight bearing which was gradually moved down to the feet in order to achieve a gradual increase in exercise intensity. Finally, subjects performed exercise involving reciprocal back and forth travel of the arms and legs. This exercise improves control of the abdominal muscles ${ }^{1)}$.

In order to avoid any effect on other parts of the head and body, measurement of ROM of shoulder flexion and abduction was performed by the measurer while subjects were sitting in a neutral position. A Dual Inclinometry ( $\mathrm{J}$ Tech, Dualer IQ ${ }^{\mathrm{TM}}$ Digital Inclinometer) device was used for measurement of the subject's active performance without pain. In this study, the action was repeated three times, followed by measurement of shoulder joint flexion, and the mean value was used.

A digital manual muscle tester (model 01163, Lafayette, USA, 2003) was used for measurement of the muscle strength of the upper limb. Muscle strength was measured in a neutral sitting position without movement of the neck or body, with the shoulder in abduction of $90^{\circ}$. The strength of shoulder abduction was measured three times, with a resting period of 30 seconds between each measurement and the mean value was used.

A grasping power meter (digital grasping power meter, DHS-176, Gilwoo Detect company, USA) was used for the measurement of the grasping power of the middle finger. The subject maintained a neutral position while sitting on a chair with a backrest, with the arm in a natural position, and the second joint of the middle finger was held at a right angle and was pulled forcefully. Measurements were performed three times, and the mean value was recorded.

The SPSS 17.0 program was used for statistical analyses. The Shapiro-Wilk test was used to determine the distribution of the general properties and outcome measures of the subjects. The paired t test was used to compare the pretest and posttest results of range of motion, muscle strength, and grasping power within each group, and the independent $t$ test was performed to compare the two groups before and after training. A $\mathrm{p}$ value $<0.05$ was considered significant.

\section{RESULTS}

In the experimental group, superior side flexion ROM was $160.27^{\circ}$ before training, and $164.87^{\circ}$ after training, a statistically significant increase of $4.6^{\circ}(\mathrm{p}<0.05)$. In the experimental group, inferior side flexion was $157.28^{\circ}$ before training, and $163.14^{\circ}$ after training, a statistically significant increase of $5.85^{\circ}(\mathrm{p}<0.05)$. In the experimental group, superior side abduction $\mathrm{ROM}$ was $151.85^{\circ}$ before training, and $156.94^{\circ}$ after training, a statistically significant increase of $5.09^{\circ}(p<0.05)$. In the experimental group, inferior side abduction ROM was $147.36^{\circ}$ before training, and $155.68^{\circ}$ after training, a statistically significant increase of $8.33^{\circ}$, $(\mathrm{p}<0.05)$.

In the experimental group, superior side muscle strength was $29.66 \mathrm{~kg}$ before training, and $36.72 \mathrm{~kg}$ after training, a statistically significant increase of $7.06 \mathrm{~kg}(\mathrm{p}<0.05)$. In the experimental group, inferior side muscle strength was $28.46 \mathrm{~kg}$ before training, and $31.53 \mathrm{~kg}$ after training, a sta- 
Table 1. Comparison of ROM, muscle strength, and grasping power

$(n=22)$

\begin{tabular}{|c|c|c|c|c|c|c|}
\hline \multirow{3}{*}{ Parameters } & \multicolumn{4}{|c|}{ Values } & \multicolumn{2}{|c|}{ Change Values } \\
\hline & \multicolumn{2}{|c|}{$\begin{array}{l}\text { Shoulder stability exercise group } \\
\qquad(\mathrm{n}=11)\end{array}$} & \multicolumn{2}{|c|}{$\begin{array}{l}\text { Control group } \\
\qquad(\mathrm{n}=11)\end{array}$} & \multirow{2}{*}{$\begin{array}{c}\text { Shoulder stability } \\
\text { exercise group } \\
(\mathrm{n}=11)\end{array}$} & \multirow{2}{*}{$\begin{array}{l}\begin{array}{c}\text { Control group } \\
(\mathrm{n}=11)\end{array} \\
\text { Post-Pre }\end{array}$} \\
\hline & Pre & Post & Pre & Post & & \\
\hline $\begin{array}{l}\text { ROM flexion } \\
\text { superior side }\left(^{\circ}\right)\end{array}$ & $160.27(11.40)^{\mathrm{a}}$ & $164.87(9.52)^{*}$ & $152.61(11.74)$ & $152.97(11.31)$ & $4.60(4.12)^{*}$ & $0.36(0.77)$ \\
\hline $\begin{array}{l}\text { ROM flexion } \\
\text { inferior side }\left(^{\circ}\right)\end{array}$ & $157.28(12.40)$ & $163.14(9.21)^{*}$ & $152.88(12.45)$ & $153.35(12.42)$ & $5.85(3.63)^{*}$ & $0.46(1.11)$ \\
\hline $\begin{array}{l}\text { ROM abduction } \\
\text { superior side }\left(^{\circ}\right)\end{array}$ & $151.85(16.55)$ & $156.94(14.09)^{*}$ & $140.37(17.32)$ & $140.66(17.27)$ & $5.09(4.57)^{*}$ & $0.29(0.49)$ \\
\hline $\begin{array}{l}\text { ROM abduction } \\
\text { inferior side }\left(^{\circ}\right)\end{array}$ & $147.36(26.33)$ & $155.68(19.89)^{*}$ & $141.56(18.16)$ & 141.71 (17.87) & $8.33(8.65)^{*}$ & $0.15(0.49)$ \\
\hline $\begin{array}{l}\text { muscle strength } \\
\text { superior side }(\mathrm{kg})\end{array}$ & $29.66(25.69)$ & $36.72(23.87)^{*}$ & 16.73 (11.46) & 17.13 (11.22) & $7.06(4.49)^{*}$ & $0.40(0.66)$ \\
\hline $\begin{array}{l}\text { muscle strength } \\
\text { inferior side }(\mathrm{kg})\end{array}$ & $28.46(24.27)$ & $36.31(21.14)^{*}$ & $18.15(13.55)$ & $18.52(12.77)$ & $7.85(5.50)^{*}$ & $0.37(0.93)$ \\
\hline $\begin{array}{l}\text { grasping power } \\
\text { superior side }(\mathrm{kg})\end{array}$ & $27.36(14.95)$ & $31.53(14.38)^{*}$ & $36.51(14.74)$ & $36.80(15.01)$ & $4.17(1.68)^{*}$ & $0.29(0.77)$ \\
\hline $\begin{array}{l}\text { grasping power } \\
\text { inferior side }(\mathrm{kg})\end{array}$ & $0.24(12.70)$ & $30.76(12.44)^{*}$ & 34.78 (11.39) & 35.05 (10.94) & $4.63(1.51)^{*}$ & $0.26(0.63)$ \\
\hline
\end{tabular}

Values are ${ }^{a}$ mean (SD). ROM: range of motion, flexion: shoulder flexion, abduction: shoulder abduction, muscle strength: muscle strength of shoulder abduction, grasping power: second joint of the middle finger was held at a right angle and was pulled forcefully, superior side: the side exhibiting the least pain was called the superior side, inferior side: the side exhibiting the greatest pain was called the inferior side, ${ }^{*} \mathrm{p}<0.05$

tistically significant increase of $4.17 \mathrm{~kg}(\mathrm{p}<0.05)$.

In the experimental group, superior side grasping power was $27.36 \mathrm{~kg}$ before training, and $31.53 \mathrm{~kg}$ after training, a statistically significant increase of $4.17 \mathrm{~kg}(\mathrm{p}<0.05)$. In the experimental group, inferior side grasping power was $26.13 \mathrm{~kg}$ before training, and $30.76 \mathrm{~kg}$ after training, a statistically significant increase of $4.63 \mathrm{~kg}(\mathrm{p}<0.05)$.

Significant differences in ROM, muscle strength, and grasping power were observed between the experimental and control groups $(\mathrm{p}<0.05)$ (Table 1$)$.

\section{DISCUSSION}

Kisner and Colby ${ }^{1)}$ suggested elevation/depression, protraction and retraction, upward rotation and downward rotation of the scapula and flexion, abduction and external rotation exercise of the shoulder joint with open-chain stabilization exercise and push-up on the floor and wall with closed-chain stabilization exercise, static strengthening, and functional activity. According to Dewhurst ${ }^{13}$, in patients with impingement syndrome, changes in functional ability of the muscles can aggravate the illness, and the factors affecting the subacromial space are a shortened pectoralis muscle, levator scapulae, thoracic vertebra kyphosis and bad posture. They proprsed strengthening of the suprasupinatus, and the compressive pressure of the scapulohumeral joint, as a remedy, and noted that stability and mobility of the infraspinatus, teres minor, and subscapularis, which is a rotator cuff muscle, and the interaction of the serratus anterior, upper trapezius, and lower trapezius are required for effective adaption of scapular rotation

McClure et al. ${ }^{4}$ conducted a progressive exercise program for a period of six weeks, in which subjects performed resistive muscle strengthening, stretching, and posture exercise and received education in the performance of a home exercise program. After the intervention, the subjects range of motion of internal rotation, external rotation, and abduction showed significant increases $(p<0.001)$, Ginn et al. ${ }^{14)}$ compared an exercise group and a control group, in a study using exercises for the rotator cuff of the shoulder joint muscle, which is critical for shoulder joint stability, and evaluated function, stretching of shortened muscles, and strengthening of weakened muscles. Reeducation for the scapulohumeral rhythm was also conducted during performance of the upper limb exercise. Subjects in the exercise group showed a significant increase $(p<0.001)$ in ROM, ROM showed an increase of $22^{\circ}(\mathrm{p}=0.006)$ without pain, and flexion showed an increase of $11^{\circ}(\mathrm{p}=0.04)$. Lombardi et al. ${ }^{15)}$, who conducted a study of subjects who performed progressive resistance exercise for flexion, extension, internal rotation, and external rotation two times a week for a period of two months, reported a significant increase in the subjects' range of motion of abduction and extension $(p=0.001, p=0.022)$. In our present study, a significant increase was observed in the range of motion of subjects in the experimental and control groups who performed stability exercise for the shoulder $(p<0.05)$. The range of motion showed a significant increase $(\mathrm{p}<0.05)$ after participation in the exercise program, which was in agreement with results reported in previous research. 
Wang et al. ${ }^{16)}$ instructed patients in performance of muscle strengthening and stretching, and reported a significant increase of muscle strength in horizontal abduction, internal rotation, and external rotation $(\mathrm{p}<0.01)$. Başkurt $\left.{ }^{17}\right)$ conducted stretching, strengthening exercise, and scapular stabilization exercise for patients with shoulder joint syndrome. Their experimental subjects showed a significant increase $(p<0.005)$ in muscle strength. Our present study compared subjects in an experimental group and a control group who performed stability exercises for the shoulder. Our experimental subjects showed a significant increase in muscle strength $(p<0.05)$, compared with before performance of the stability exercise, in agreement with results reported in previous research. This result indicates that interaction and combination of forces around the shoulder joint work effectively in the performance of stability exercise, effectively improving muscle strength.

Sporrong et al. ${ }^{18)}$ suggested that the grasping power test is very useful in the clinical evaluation of patients with shoulder joint pain. In our present study, one patient could not perform 180 degrees of shoulder joint. Therefore, grasping power was measured in a relaxed position, in which both arms were placed naturally beside the body. Subjects in the exercise and control groups who performed stability exercise for the shoulder showed a significant increase $(p<0.05)$ in grasping power, compared with before performance of the stability exercise.

The results of our present research indicate there are significant effects of shoulder stability exercise with regard to increase of range of motion, muscle strength, and grasping power. This research provides useful data on shoulder joint damage and prevention of damage to the shoulder joint for practitioners in clinical rehabilitation.

\section{REFERENCES}

1) Kisner C, Colby LA: Therapeutic exercise. Foundations and Techniques. Philadelphia: Davis Company, 2007.

2) McClure PW, Michener LA, Karduna AR: Shoulder function and 3-dimen- sional scapular kinematics in people with and without shoulder impingement syndrome. Phys Ther, 2006, 86: 1075-1090. [Medline]

3) Ludewig PM, Cook TM: Alterations in shoulder kinematics and associated muscle activity in people with symptoms of shoulder impingement. Phys Ther, 2000, 80: 276-291. [Medline]

4) McClure PW, Bialker J, Neff N, et al.: Shoulder function and 3-dimensional kinematics in people with shoulder impingement syndrome before and after a 6-week exercise program. Phys Ther, 2004, 84: 832-848. [Medline]

5) Sahrmann SA: Does postural assessment contribute to patient care? J Orthop Sports Phys Ther, 2002, 32: 376-379. [Medline]

6) Cools AM, Witvrouw EE, Danneels LA, et al.: Does taping influence electromyographic muscle activity in the scapular rotators in healthy shoulder. Man Ther, 2002, 7: 154-162. [Medline] [CrossRef]

7) Cools AM, Geerooms E, Declercq GA, et al.: Isokinetic scapular muscle performance in young elite Gymnasts. J Athl Train, 2007, 42: 458-463. [Medline]

8) Lin JJ, Hanten WP, Olson SL, et al.: Shoulder dysfunction assessment: self-report and impaired scapular movements. Phys Ther, 2006, 86: 10651074. [Medline]

9) Ludewig PM, Borstad JD: Effects of a home exercise programme on shoulder pain and functional status in construction workers. Occup Environ Med, 2003, 60: 841-849. [Medline] [CrossRef]

10) Arlotta M, Lovasco G, McLean L: Selective recruitment of the lower fibers of the trapezius muscle. J Electromyogr Kinesiol, 2011, 21: 403-410. [Medline] [CrossRef]

11) Kendall FP, McCreary EK, Provance PG: Muscle: Testing and function with posture and pain. Baltimore: Williams \& Wilkins, 2005.

12) Borstad JD, Ludewig PM: Comparison of three stretches for the pectoralis minor muscle. J Shoulder Elbow Surg, 2006, 15: 324-330. [Medline] [CrossRef]

13) Dewhurst A: An exploration of evidence-based exercises for shoulder impingement syndrome. Int Musculoskelectal Med, 2010, 32: 111-116. [CrossRef]

14) Ginn KA, Herbert RD, Khouw W, et al.: A randomized, controlled clinical trial of a treatment for shoulder pain. Phys Ther, 1997, 77: 802-809. [Medline]

15) Lombardi I, Magri AG, Fleury AM, et al.: Progressive resistance training in patients with shoulder impingement syndrome: a randomized controlled trial. Arthritis Rheum, 2008, 59: 615-622. [Medline] [CrossRef]

16) Wang $\mathrm{CH}$, McClure P, Pratt NE, et al.: Stretching and strengthening exercise: their effect on 3-D scapular kinematics. Arch Phys Med Rehabil, 1999, 80: 923-929. [Medline] [CrossRef]

17 Başkurt Z, Başkurt F, Gelecek N, et al.: The effectiveness of scapular stabilization exercise in the patients with subacromial impingement sydrome. J Back Musculoskeletal Rehabil, 2011, 24, 173-179.

18) Sporrong H, Palmerud G, Herbert P.: Hand grip increases shoulder muscle activity, An EMG analysis with static hand contraction in 9 subjects. Acta Orthop Scand, 1996, 67: 485-490. [Medline] [CrossRef] 